\title{
Study for wave force on pile holder support structure with different construction states
}

\author{
Cheng Peng ${ }^{1, a}$, Bin Yu, ${ }^{1, b}$ and Yina Wang ${ }^{1, c}$ \\ ${ }^{1}$ Key Laboratory of Engineering Sediment of Ministry Communications, Tianjin Research Institute \\ for Water Transportation Engineering; No.2618, Xingang Erhao Road, Tianjin, 300456, China \\ apengcheng3127@163.com, b416556570@qq.com, 'c172608875@qq.com
}

Keywords: Wave force; Pile holder support structure; Construction stages; Horizontal force; Uplift force; Physical model.

Abstract. In this research, a two-dimension physical model experiment was conducted, which studied the wave force characteristics on steel pipe pile under three different construction stages. The experiment results show that the single pile horizontal force maximum and sub-maximum and total horizontal force maximum are going down as the slope pavement construction, which indicates that the wave force on steel pipe pile appears in the early stage of construction. It is necessary to pay attention to protection work under extreme wave conditions.

\section{Introduction}

In the construction process, the pile holder support structure should be installed timely after steel pipe pile construction. The main roles of pile holder support structure are to prevent the excessive pile displacement of steel pipe pile which is due to the lateral pressure by riprapping construction and prevent the wave damage to the steel pipe pile without protection of riprap and armor blocks. Therefore, it is necessary to study the wave force on pile holder support structure to ensure the safety of steel pipe pile construction. The existing research about wave force on piles is mainly from physical model, formula computing and numerical model aspects. J Huang [1] studied the influence of wave force to the integrated structure of the high-pile wharf in 2010. Y Tsuchiya [2] studied the total wave force on a vertical circular in 2010. G Moe [3] studied the long-term wave force statistics for a vertical pile in 1978. Most researches are based on the construction completed status but less in the construction process. This research is based on the pile holder support structure of different design elevation to study the horizontal force and uplift force under different construction stages.

\section{Equipment and model arrangement}

The experiment is carried out in a wave flume. The flume is $68.0 \mathrm{~m}$ long, $1.0 \mathrm{~m}$ wide and $1.5 \mathrm{~m}$ high. At one end of the flume, the wave generator is set, the regular and irregular waves can be generated. Both ends of wave flume are equipped with the wave-absorption devices. The wave pressure is measured by point pressure sensor of Hydrodynamic Data Collection System named TK2008.

The caisson top elevation is $+2.0 \mathrm{~m}$. 7 rows and 7 columns of total 49 steel pipe piles are set evenly spaced in front of the caisson. The pile holder support structure is above the steel pipe piles, which design elevations are $+3.0 \mathrm{~m}$ and $+5.0 \mathrm{~m}$. Three different construction stages are selected for the experiment. Section 1 is uncovered; section 2 is a semi-riprap protection, rocks are laid before the caisson; section 3 is standard design section, rocks and armor blocks are placed to cover the slope. The pile holder support structure's layout and cross section under three states are shown in Fig. 1.

*Corresponding author.

E-mail address: 416556570@qq.com (Bin Yu) 


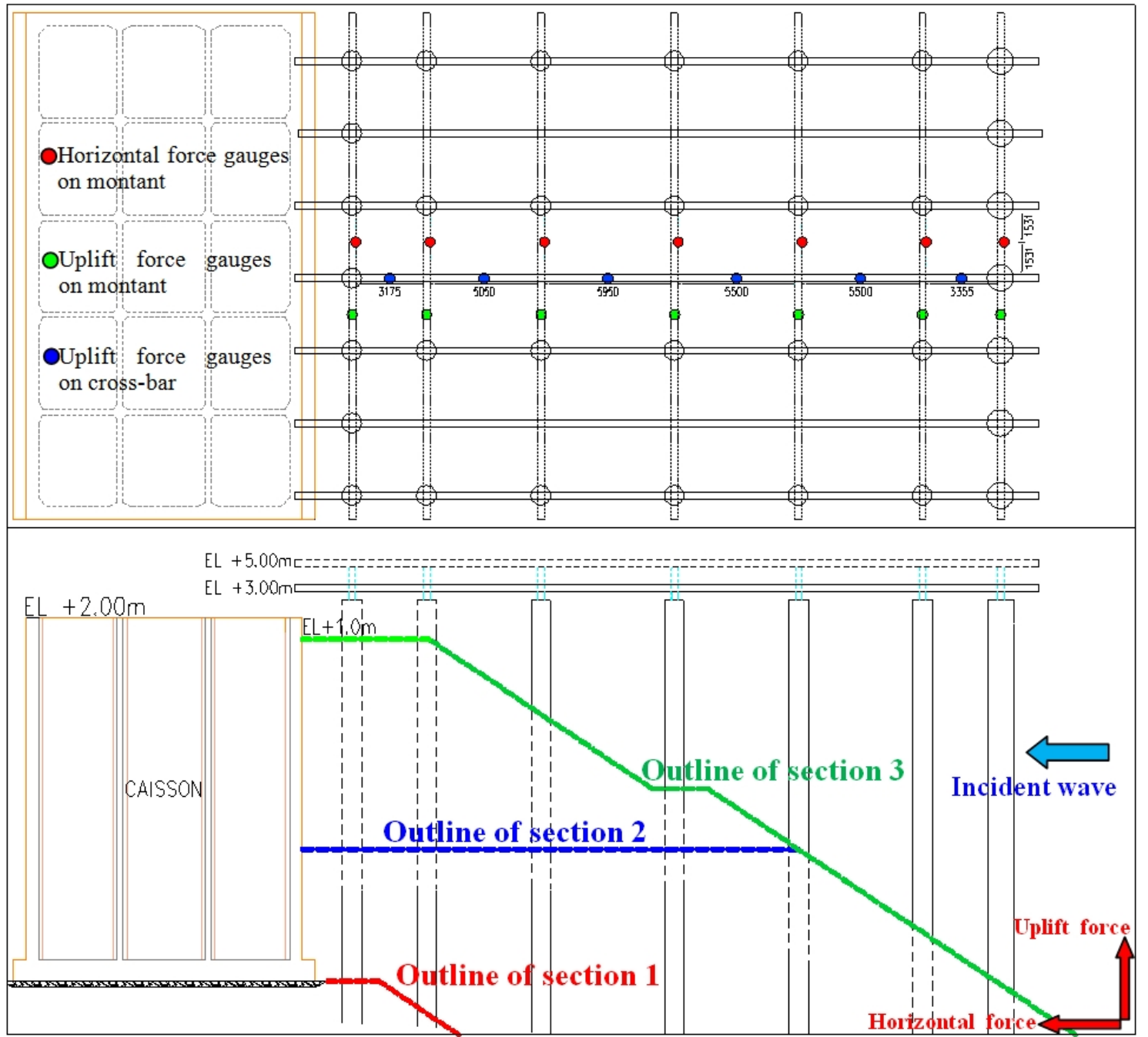

Fig. 1 Model arrangement and pressure sensor layout of pile holder support structure

\section{Wave condition}

The wave condition includes water level, wave height, wave period, wave type and spectrum is shown in Tab. 1. The physical model must satisfy gravitational similarity [4] and geometry similarity [5]. In this experiment, the geometry scale is 25 , that is mean the depth scale, wave weight scale and wave length scale all are 25 , the period scale is 5 and the force scale is 15625 .

Tab. 1 Wave condition of physical model

\begin{tabular}{ccccc}
\hline Water level $(\mathrm{m})$ & $\mathrm{H}_{\mathrm{s}}(\mathrm{m})$ & $\mathrm{T}_{\mathrm{s}}(\mathrm{s})$ & Wave type & Spectrum \\
\hline 1.0 & 5.75 & 12.20 & Irregular wave & Jonswap \\
\hline
\end{tabular}

\section{Analysis method of wave force}

In the experiment, the montant and the cross-bar of pile holder support structure are defined to perpendicular and parallel to incident wave direction respectively. For the coordinate system of wave force, the horizontal force and the uplift force positive direction are defined to parallel and perpendicular and upward to incident wave direction respectively. Considering the pile diameter is small (diameter is $0.3 \mathrm{~m}$ ), seven pressure measuring points were laid on the seaside of montant to measure the horizontal force and seven pressure measuring points were laid below the montant to measure the uplift force. As well, six pressure measuring points were laid below the cross-bar to measure the uplift force. Therefore, a total of 20 pressure sensors are laid on the pile holder support structure. The sensors of horizontal force and uplift force on the montant are named No. 1 No. 7 
respectively, and the sensors of uplift force on the cross-bar is named No. 1 No. 7. The sensor layout is shown in Fig. 1 in the previous paragraph.

\section{Experiment phenomenon}

For instance of pile holder support structure elevation is $+5.0 \mathrm{~m}$, in section 1, wave impact the caisson and pile holder support structure directly after through the pile group, and overtopping happened on the top of caisson. In section 2, wave climbed slightly along the underwater slope and then impacted the caisson and pile holder support structure. In section 3, because the elevation between caisson and armor layer are basically the same, the wave climbed along the armor blocks and cross the caisson straight, and the less impact on the pile holder support structure. The experiment phenomenons under three construction stages are shown in Fig. 2.
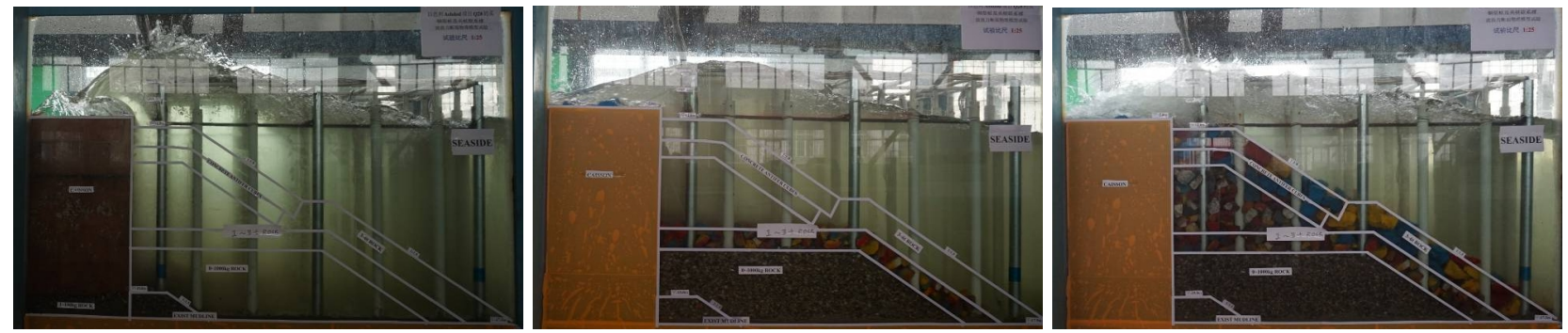

Fig.2 Experiment phenomenon under three construction stages (From left to right are section 1, section 2 and section 3)

\section{Results of horizontal force on the montant}

The results of horizontal force on the montant as the pile holder support structure elevation is $+3.0 \mathrm{~m}$ are shown in Fig. 3 left picture. The maximum force occurs on No.7 pile which is closed to the caisson, the value are $13.26 \mathrm{kN} / \mathrm{m}, 16.29 \mathrm{kN} / \mathrm{m}$ and $17.46 \mathrm{kN} / \mathrm{m}$ in section 1 , section 2 and section 3 . This due to the cover effect of stones and armor blocks are increase with the slop shape from no-riprap to semi-riprap then to the full coverage of armor blocks, which lead to the uplift impact of waves decreased and the horizontal impact of waves increased.

The results of horizontal force on the montant as the pile holder support structure elevation is $+5.0 \mathrm{~m}$ are shown in Fig. 3 right picture. The maximum force occurs on No.7 pile which is closed to the caisson, the value are $7.63 \mathrm{kN} / \mathrm{m}, 6.64 \mathrm{kN} / \mathrm{m}$ and $6.28 \mathrm{kN} / \mathrm{m}$ in section 1 , section 2 and section 3 . This due to the pile holder support structure elevation increased to $+5.0 \mathrm{~m}$, wave's impact the montant in section 3 which the horizontal force dominated is weaker than the wave's impact the montant in section 1 and 2 which the uplift force dominated. So the horizontal impact of waves decreased as the armor blocks covered.
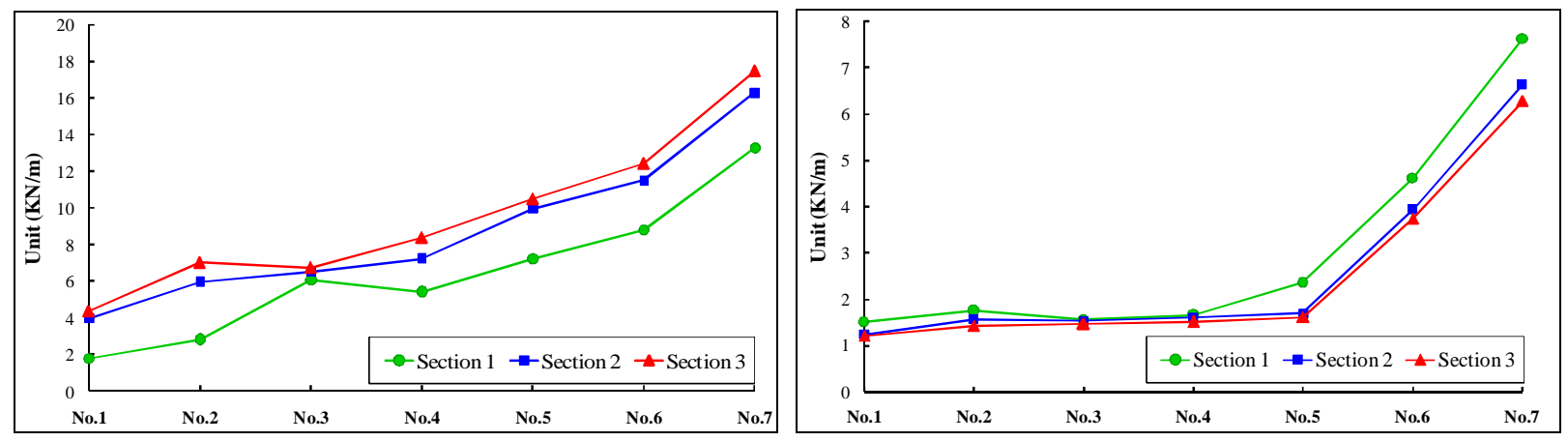

Fig. 3 Results of horizontal force on montant (From left to right are $\mathbf{+ 3 . 0 m}$ and $\mathbf{+ 5 . 0 m}$ elevation) 


\section{Results of uplift force on the montant}

The results of uplift force on the montant as the pile holder support structure is shown in Fig. 5. The maximum force occurs on No.7 pile which is closed to the caisson, the value are $18.17 \mathrm{kN} / \mathrm{m}$, $13.28 \mathrm{kN} / \mathrm{m}$ and $7.22 \mathrm{kN} / \mathrm{m}$ in section 1 , section 2 and section 3 as the elevation is $+3.0 \mathrm{~m}$; the maximum force occurs on No.7 pile which is closed to the caisson, the value are $13.09 \mathrm{kN} / \mathrm{m}, 9.78 \mathrm{kN} / \mathrm{m}$ and $3.17 \mathrm{kN} / \mathrm{m}$ in section 1 , section 2 and section 3 as the elevation is $+5.0 \mathrm{~m}$. This due to the cover effect of stones and armor blocks to steel pipe piles is increase with the slop shape from no-riprap to semi-riprap then to the full coverage of armor blocks, which lead to uplift force decreased. Besides, because of the pile holder support structure elevation increase, the uplift force of elevation is $+3.0 \mathrm{~m}$ are generally greater than elevation is $+5.0 \mathrm{~m}$, this shows that the vertical wall reflection has a direct influence on the uplift force on the montant.
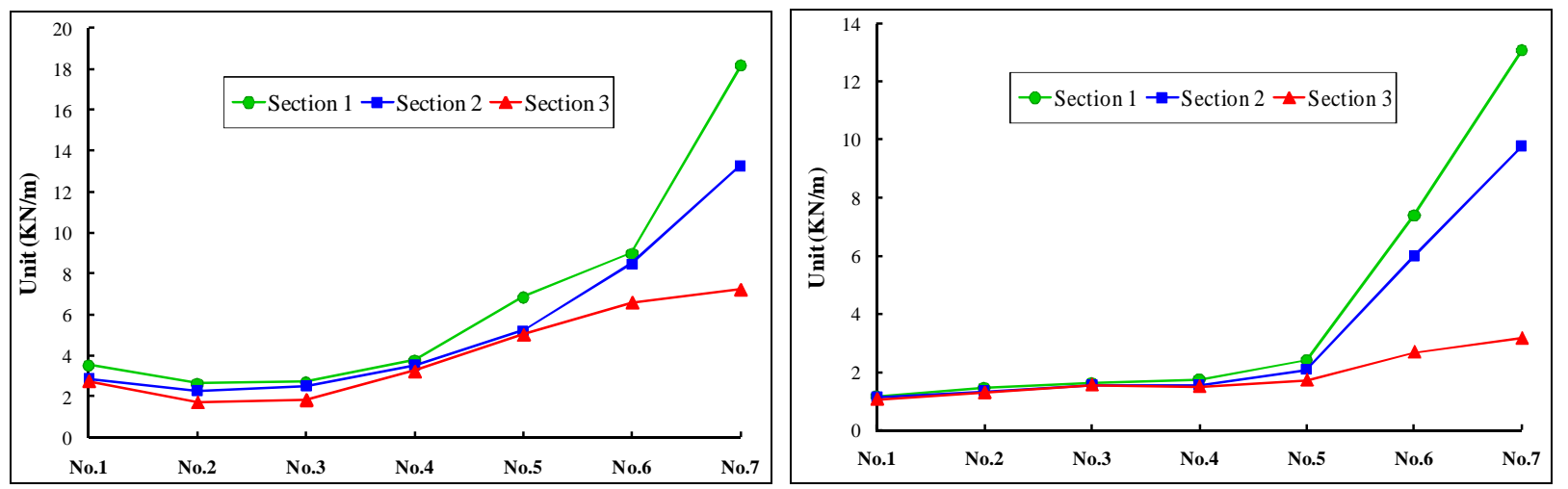

Fig. 4 Results of uplift force on the montant

(From left to right are $\mathbf{+ 3 . 0 m}$ and $\mathbf{+ 5 . 0 m}$ elevation)

\section{Results of uplift force on the cross-bar}

The results of uplift force on the cross-bar as the pile holder support structure is shown in Fig. 5. The maximum force occurs in section 1 , the values are $10.73 \mathrm{kN}$ and $7.22 \mathrm{kN}$ as the elevation are $+3.0 \mathrm{~m}$ and $+5.0 \mathrm{~m}$. The relationship of uplift force on the cross-bar is consistent with it on the montant, because of the pile holder support structure elevation increase, the uplift force of elevation is $+3.0 \mathrm{~m}$ are generally greater than elevation is $+5.0 \mathrm{~m}$. Besides, the uplift force on the cross-bar decreased with the slope cover of rocks and armor blocks increased.

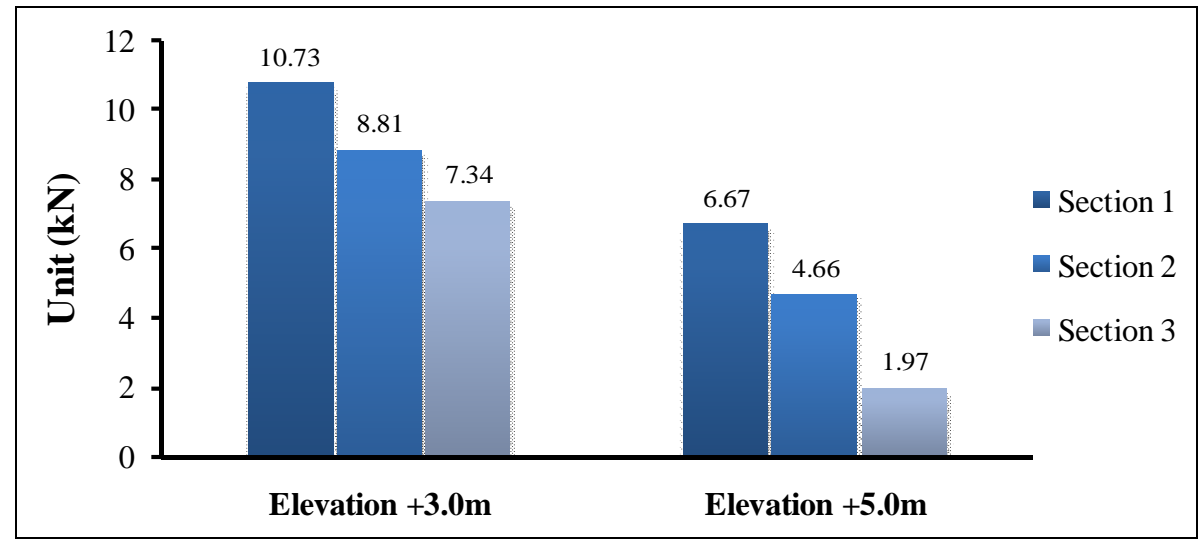

Fig. 5 Results of uplift force on the montant (From left to right are section 1 and section 2) 


\section{Conclusions}

(1) The maximum horizontal force on the montant is $17.46 \mathrm{kN} / \mathrm{m}$ appears in the seventh row of montant from sea side in section 3 as the pile holder support structure elevation is $+3.0 \mathrm{~m}$. The relationship of horizontal force in three sections is section 1 is less than section 2 and less than section 3 as the elevation is $+3.0 \mathrm{~m}$; section 1 is greater than section 2 and greater than section 3 as the elevation is $+5.0 \mathrm{~m}$. (2) The maximum uplift force on the montant is $18.17 \mathrm{kN} / \mathrm{m}$ appears in the seventh row of montant from sea side in section 1 as the pile holder support structure elevation is $+3.0 \mathrm{~m}$. The relationship of uplift force in three sections is section 1 is greater than section 2 and greater than section 3 as the elevation is $+3.0 \mathrm{~m}$ and $+5.0 \mathrm{~m}$. The uplift force of elevation is $+3.0 \mathrm{~m}$ are generally greater than elevation is $+5.0 \mathrm{~m}$. (3) The maximum uplift force on the cross-bar is $10.73 \mathrm{kN}$ appears in section 1 as the pile holder support structure elevation is $+3.0 \mathrm{~m}$. And the regularity of the results of maximum uplift on the cross-bar is the same as it on the montant. (3)The results indicate that the wave force on the pile holder support structure mainly appears in the early stage of construction. It is necessary to pay attention to protection work under extreme wave conditions.

\section{Acknowledgements}

The authors gratefully acknowledge the financial support provided by Central Commonweal Research Institute Basic R\&D Special Foundation of TIWTE (Grant No. TKS 160107); Applied Basic Research Project funded by Ministry of Transport, China (Grant No.2014329224380); National Natural Science Foundation of China (Grant No. 51409135) and Tianjin Applied Basic and Frontier Technology Research Project (Grant No. 15JCQNJC07300).

\section{References}

[1] Huang J, Yu X, Chen Z. Analysis on Impact of Wave Force to High-pile Wharf Structure[J]. Port Engineering Technology, 2010.

[2] Tsuchiya Y, Yamaguchi M. Total Wave Force on a Vertical Circular Cylindrical Pile[J]. American Society of Civil Engineers, 2010, 1974(227):11-21.

[3] Moe G. Long-term wave-force statistics for a vertical pile[J]. Coastal Engineering, 1978, 2(4):297-311.

[4] BS 6349: British Standard Code of Practice for Maritime Structure, British Standards Institution.

[5] Users Guide to Physical Modelling and Experimentation. L.E Frostick, S.J. Mclell and T.G. Mercer. Published by CRC Pres. ISBN 978-0-415-60912-8. 